\title{
Dual NEP/ECE inhibition improves endothelial function in mesenteric resistance arteries of 32-week-old SHR
}

\author{
Pieter Lemkens ${ }^{1}$, Leon JA Spijkers ${ }^{2}$, Merlijn J Meens ${ }^{1,3,4}$, Jelly Nelissen ${ }^{1}$, Ben Janssen ${ }^{1}$, Stephan LM Peters ${ }^{2}$, \\ Paul MH Schiffers ${ }^{1}$ and Jo GR De Mey ${ }^{1,5}$
}

Endothelin 1 (ET-1), a potent vasoconstrictor, pro-mitogenic and pro-inflammatory peptide, may promote development of endothelial dysfunction and arterial remodeling. ET-1 can be formed through cleavage of big-ET-1 by endothelin-converting enzyme (ECE) or neutral endopeptidase (NEP). We investigated whether chronic treatment with the novel dual NEP/ECE inhibitor SOL1 improves functional and structural properties of resistance-sized arteries of 32-week-old male spontaneously hypertensive rats (SHR). SHR received a chronic 4-week treatment with SOL1, losartan or hydralazine. We then compared effects of

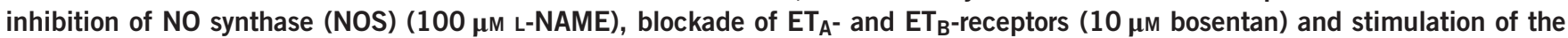
endothelium with $0.001-10 \mu \mathrm{M}$ acetylcholine $(\mathrm{ACh})$ in isolated third-order mesenteric resistance arteries. Losartan and hydralazine significantly lowered blood pressure. Losartan decreased the media-to-lumen ratio of resistance arteries. L-NAME (1) increased arterial contractile responses to $\mathrm{K}^{+}(5.9-40 \mathrm{~mm})$ in the losartan, SOL1 and vehicle group and (2) increased the sensitivity to phenylephrine (PHE; $0.16-20 \mu \mathrm{m}$ ) in the SOL1 group but not in the losartan, hydralazine and vehicle group. Relaxing responses to ACh in the absence or presence of L-NAME during contractions induced by either $10 \mu \mathrm{M}$ PHE or $40 \mathrm{~mm} \mathrm{~K}^{+}$ were not altered by any in vivo treatment. Acute treatment with bosentan did, however, significantly improve maximal relaxing responses involving endothelium-derived nitric oxide and -hyperpolarizing factors in the SOL1 group but not in the losartan, hydralazine or vehicle group. Thus, chronic inhibition of NEP/ECE improved basal endothelial function but did not alter blood pressure, resistance artery structure and stimulated endothelium-dependent relaxing responses in 32-week-old SHR. Hypertension Research (2017) 40, 738-745; doi:10.1038/hr.2017.38; published online 16 March 2017

Keywords: bosentan; EDHF; endothelin-1; losartan; NO

\section{INTRODUCTION}

The endothelium can produce vasoactive compounds that influence the underlying layer of smooth muscle cells modulating vasomotor responses to control blood pressure and local blood flow. Endothelium-derived vasoactive factors include vasodilators, such as nitric oxide (NO), endothelium-derived hyperpolarizing factors (EDHF) and prostacyclin, and vasoconstrictors, such as endoperoxides and endothelin-1 (ET-1)., ${ }^{1,2}$ Endothelial dysfunction is classically described as (i) an impairment of endothelium-dependent relaxing responses and (ii) an enhanced sensitivity to vasoconstrictors. In many forms of human and experimental hypertension, endothelial dysfunction and arterial remodeling are considered key players in the development and maintenance of high blood pressure. ${ }^{3-5}$ In spontaneously hypertensive rats (SHR) a well-described manifestation of endothelial dysfunction is an increased production of endotheliumderived contractile factors (EDCF). ${ }^{6}$
Drug-intervention studies have shown that some anti-hypertensive treatments, for instance with angiotensin $\mathrm{AT}_{1}$ receptor antagonists, not only lower blood pressure but also cause an improvement of endothelial function and regression of structural changes in resistance arteries. $^{7,8}$ Other anti-hypertensive treatments, for example, the selective $\beta_{1}$-adrenoceptor antagonist atenolol, succeed in lowering blood pressure but did not reverse the structural changes or the endothelial dysfunction associated with hypertension. In other words, for reversing adverse effects associated with hypertension, lowering blood pressure alone is not sufficient. ${ }^{9,10}$

Studies from our group showed that the level of the endotheliumderived peptide ET-1 is increased in several organs during the development of hypertension in SHR; importantly, the levels of ET-1 are increased in several organs. ${ }^{11}$ Apart from being a potent vasoconstrictor, ET-1 is also a potent growth promoting and pro-inflammatory agent. ${ }^{12-16}$ Because of these actions, ET-1 is of

${ }^{1}$ Department of Pharmacology and Toxicology, Cardiovascular Research Institute Maastricht, Maastricht University, Maastricht, The Netherlands; ${ }^{2}$ Department of Pharmacology and Pharmacotherapy, Academic Medical Center, Amsterdam, The Netherlands; ${ }^{3}$ Department of Pathology and Immunology, University of Geneva, Geneva, Switzerland; ${ }^{4}$ Department of Medical Specialties-Cardiology, University of Geneva, Geneva, Switzerland and ${ }^{5}$ Department of Cardiovascular and Renal Research, Institute of Molecular Medicine, University of Southern Denmark, Odense, Denmark

Correspondence: JGR De Mey, Department of Cardiovascular and Renal Research, Institute of Molecular Medicine, J.B. Winsløws Vej 21/3, Odense, University of Southern Denmark, Odense, DK 5000 C, Denmark.

E-mail: jdemey@health.sdu.dk

Received 30 August 2016; revised 22 December 2016; accepted 23 January 2017; published online 16 March 2017 
interest in the development of endothelial dysfunction and hypertension-related arterial remodeling. ET-1 can be formed through cleavage of big-ET-1 by endothelin-converting enzyme (ECE). Alternatively, big-ET-1 can be hydrolyzed by chymase or matrix metalloproteinase 2 to form ET-1 (1-31) or ET-1 (1-32), respectively. Both are further processed into ET-1 by neutral endopeptidase (NEP). ${ }^{17-19}$ Thus, a dual NEP/ECE inhibitor, for example the novel compound SOL1, reduces ET-1 production by inhibiting all three pathways. ${ }^{20}$ Recently, Kalk et al. ${ }^{21}$ reported that the dual NEP/ECE inhibitor daglutril (SLV338, an analog of SOL1) reduced cardiomyocyte hypertrophy, interstitial fibrosis and perivascular fibrosis in the 2-kidney 1-clip model of hypertension.

Here, we tested the hypothesis that ET-1 contributes to endothelial dysfunction, arterial remodeling and hypertension in established essential hypertension. We therefore compared the effects of chronic treatment with the vasodilator hydralazine, the $\mathrm{AT}_{1}$ receptor antagonist losartan or the dual NEP/ECE inhibitor SOL1 on functional and structural properties of mesenteric resistance arteries from chronically hypertensive (32-week old) SHR.

\section{METHODS}

\section{Animals, model and surgery}

Twenty-eight-week-old male SHR were obtained from Charles River (Maastricht, NL, USA). All experiments were performed in accordance with the ethical committee for animal welfare of Maastricht University. The rats were anesthetized with isoflurane (1-4\%) and osmotic minipumps (2ML4 pumps, Alzet, Cupertino, CA, USA) were subcutaneously implanted for chronic continuous drug treatment during the next 4 weeks. Preliminary dose-finding experiments were carried out to identify an appropriate dose of the dual NEP/ECE inhibitor SOL1 (2-\{[1-(\{[(3S)-1-(carboxymethyl-2-oxo2,3,4,5-tetrahydro-1H-1-benzazepin-3-yl] amino\}carbonyl)cyclopentyl]methyl\}4-[[3-methylamino)propyl](methyl)amino]-4-oxobutanoic acid; Abbott, Hanover, Germany). A dose of $50 \mathrm{mg} \mathrm{kg}^{-1}$ per day decreased urinary ET-1 content (from $32.89 \pm 3.91$ to $1.35 \pm 0.25 \mathrm{pg} \mathrm{ml}^{-1}, P<0.001$ ). Losartan and hydralazine were administered at $20 \mathrm{mg} \mathrm{kg}^{-1}$ per day and $9 \mathrm{mg} \mathrm{kg}^{-1}$ per day, respectively. Additional hydralazine was added to the drinking water to keep the dose at $20 \mathrm{mg} \mathrm{kg}^{-1}$ per day, because the maximal solubility of hydralazine was reached in saline. In untreated SHR, a dummy device (polyethylene (PE) tube of the same size as the 2ML4 pumps) was subcutaneously implanted.2. Animals were randomly assigned to treatment groups ( $n=8$ each).

At the end of the drug treatment, blood pressure was measured in conscious unrestrained rats via a heparinized $\left(5 \mathrm{U} \mathrm{ml}^{-1}\right)$ indwelling PE catheter that was introduced into the left femoral artery 2 days before measurement. The arterial catheter was connected to a pressure transducer (Micro Switch 150 PC, Mouser Electronics, Munich Germany) and its output was sampled at $2.5 \mathrm{kHz}$. Mean arterial pressure (MAP) was calculated using the IDEEQ data-acquisition system (instrument services, Maastricht University). All animals were euthanized with isoflurane $(>4 \%)$.

\section{Arterial pressure/diameter relationships}

Animals were killed and first-order mesenteric arteries were isolated. Arteries were mounted on two glass micropipettes in an organ chamber filled with Ca-free Krebs Ringer solution (144 mM NaCl, $4.7 \mathrm{~mm} \mathrm{KCl,} 1.2 \mathrm{~mm} \mathrm{MgSO}_{4}$, $1.2 \mathrm{~mm} \mathrm{KH}_{2} \mathrm{PO}_{4}, 14.9 \mathrm{~mm}$ HEPES and $5.5 \mathrm{~mm}$ glucose; $\left.37^{\circ} \mathrm{C}, \mathrm{pH} 7.4\right)$. An aliquot of $10 \mu \mathrm{M} \mathrm{Na-nitroprusside} \mathrm{was} \mathrm{added} \mathrm{to} \mathrm{ensure} \mathrm{maximal} \mathrm{vasodilatation.}$ A pressure-diameter relationship was established by recording the lumen diameter while gradually increasing the distending pressure $(20-120 \mathrm{~mm} \mathrm{Hg}$, $10 \mathrm{~mm} \mathrm{Hg}$ steps). ${ }^{23}$ After the experiment, vessels were fixed at $80 \mathrm{~mm} \mathrm{Hg}$ in $4 \%$ phosphate buffered formaldehyde solution for $1 \mathrm{~h}$ at $37^{\circ} \mathrm{C}$ and stored in $70 \%$ ethanol.

\section{Wire myography}

Third-order mesenteric resistance arterial segments of $\sim 2 \mathrm{~mm}$ in length were isolated and mounted in wire myographs for the recording of isometric force development. ${ }^{24}$ From a portion of the arterial segments, the endothelium was mechanically removed. ${ }^{25}$ Each experiment started by progressively stretching the arterial segment to the diameter at which the largest contractile response to $10 \mu \mathrm{m}$ noradrenaline (NA) could be obtained (optimal diameter).

To prevent the sensory nerves from releasing calcitonin gene-related peptide when stimulated during potassium induced depolarizations, all arterial segments were exposed to capsaicin $(1 \mu \mathrm{M}$, during $20 \mathrm{~min}){ }^{26,27}$ Viability of the endothelium was tested by measuring acetylcholine (ACh; $10 \mu \mathrm{M})$-induced relaxation during phenylephrine (PHE)-induced contraction. Contractile responses to increasing concentrations of $\mathrm{K}^{+}(5.9-40 \mathrm{mM})$ and PHE $(0.16-20 \mu \mathrm{M})$ and relaxing responses to increasing concentrations of ACh $(0.01-10 \mu \mathrm{M})$ were recorded. The effects of nitric oxide synthase inhibition (L-N $N^{\mathrm{G}}$-nitroarginine methyl ester (L-NAME), $100 \mu \mathrm{M}$ ), cyclo-oxygenase inhibition (indomethacin (INDO), $1 \mu \mathrm{M}$ ) and a non-selective ET-receptor antagonist (bosentan $10 \mu \mathrm{M}$ ) were evaluated.

After these experiments, vessels were fixed in $4 \%$ phosphate buffered formaldehyde solution for $1 \mathrm{~h}$ at $37^{\circ} \mathrm{C}$ and stored in $70 \%$ ethanol.

\section{Histological and morphometric analysis}

Fixed first- and third-order arteries were embedded in paraffin and crosssections $(4 \mu \mathrm{m})$ were cut. All vessels were stained with Lawson's solution (Boom, Meppel, The Netherlands) to visualize the internal and external elastic laminae. The cross-sectional area of the media was determined from the circumferences of the internal and external elastic laminae. The average number of nuclear profiles in the media was determined by counting on haematoxylineosin stained cross-sections. Media thickness and media-to-lumen ratio were calculated as previously described. ${ }^{23}$

\section{Physiological solutions and drugs}

The Krebs Ringer bicarbonate-buffered physiological salt solution (Krebs Ringer buffer (KRB)) that was continuously aerated with $95 \% \mathrm{O}_{2} / 5 \%$ $\mathrm{CO}_{2}$ and maintained at $37^{\circ} \mathrm{C}$ contained (in $\mathrm{mm}$ ): $118.5 \mathrm{NaCl}, 4.7 \mathrm{KCl}$, $2.5 \mathrm{CaCl}_{2}, 1.2 \mathrm{MgSO}_{4}, 1.2 \mathrm{KH}_{2} \mathrm{PO}_{4}, 25.0 \mathrm{NaHCO}_{3}$ and 5.5 glucose. Bosentan was obtained from Actelion Pharmaceuticals (Allschwil, Switzerland) and was dissolved in DMSO. Capsaicin and INDO were purchased from Sigma Aldrich (Zwijndrecht, The Netherlands) and dissolved in ethanol. ACh, NA and PHE were purchased from Sigma and dissolved in KRB. High $\mathrm{K}^{+}$-KRB solution consisted of $\mathrm{KRB}$ in which all of the $\mathrm{NaCl}$ was replaced by $\mathrm{KCl}$. Solutions containing $10-40 \mathrm{mM} \mathrm{K}^{+}$were prepared by mixing volumes of $\mathrm{KRB}$ and $\mathrm{K}^{+}-\mathrm{KRB}$.

\section{Statistical analysis}

All contractile responses were expressed as a percentage of the maximal NA response prior to the administration of any pharmacological inhibitor. Individual concentration-response curves were fitted to a non-linear sigmoid regression curve (GraphPad Prism 5.0; La Jolla, CA, USA). Sensitivity $\left(\mathrm{pEC}_{50}\right.$ ) and maximal effect $\left(E_{\max }\right)$ are shown as mean \pm s.e.m. Two-way analysis of variances were used to compare $\mathrm{pEC}_{50}$ or $E_{\max }$. A Bonferroni post-test was used to compare multiple groups. Morphology and pressure-diameter relations are expressed as mean \pm s.e.m. Statistical significance of differences between groups was evaluated by analysis of variance (for consecutive measurements in pressure-diameter curves) or one way analysis of variance, followed by a Bonferroni or paired $t$-test (GraphPad Prism 5.0). A value of $P<0.05$ was considered to denote a statistically significant difference.

\section{RESULTS}

\section{General and arterial structural characteristics}

Body weights were not significantly altered by any treatment. MAP was significantly reduced by losartan and hydralazine treatment. It tended to be reduced by SOL1, but this did not reach statistical significance (Table 1).

Lumen diameter at $80 \mathrm{~mm} \mathrm{Hg}$ and cross-sectional area of the media of first-order mesenteric resistance arteries were comparable in vehicle-, SOL1-, losartan and hydralazine-treated animals. Media-tolumen ratio of first-order mesenteric arteries was not altered in the 
Table 1 General and arterial structural characteristics of first- and third-order mesenteric resistance arteries

\begin{tabular}{|c|c|c|c|c|}
\hline & Vehicle & SOLI & Losartan & Hydralazine \\
\hline MAP (mmHg) & $191 \pm 7$ & $172 \pm 3$ & $125 \pm 5^{a}$ & $113 \pm 14^{\mathrm{a}}$ \\
\hline $\operatorname{mCSA}\left(10^{3} \mu \mathrm{m}^{2}\right)$ & $30 \pm 3$ & $26 \pm 2$ & $24 \pm 3$ & $28 \pm 3$ \\
\hline Media-to lumen ratio & $0.184 \pm 0.014$ & $0.164 \pm 0.006$ & $0.144 \pm 0.008^{a}$ & $0.150 \pm 0.012$ \\
\hline NCC & $55 \pm 3$ & $47 \pm 2$ & $49 \pm 1$ & $52 \pm 3$ \\
\hline $\operatorname{mCSA}\left(10^{3} \mu \mathrm{m}^{2}\right)$ & $13 \pm 1$ & $14 \pm 1$ & $11 \pm 1$ & $13 \pm 1$ \\
\hline Media-to lumen ratio & $0.115 \pm 0.005$ & $0.140 \pm 0.02$ & $0.109 \pm 0.004$ & $0.109 \pm 0.004$ \\
\hline
\end{tabular}

Abbreviations: MAP, mean arterial pressure; mCSA, cross-sectional area of the media; NA, noradrenaline; NCC, cell count of the media (nuclear profiles). Results are depicted as mean + s.e.m.

a $P<0.05$ treatment vs. Vehicle.

bMaximal contractile response induced by NA.
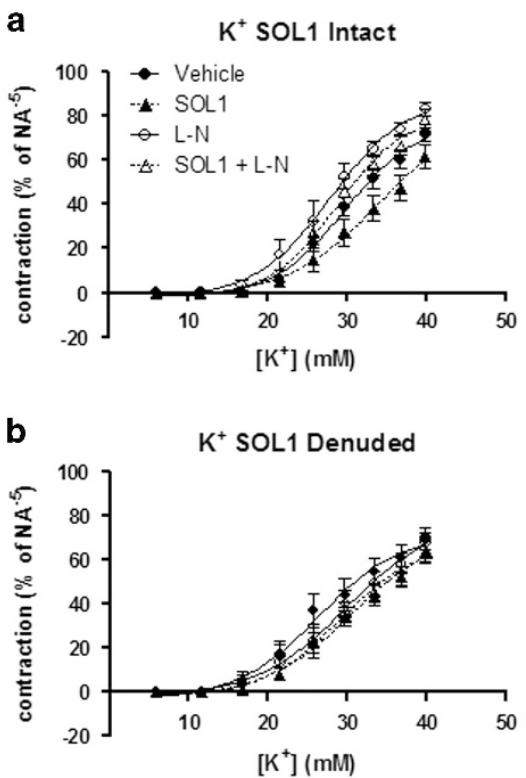

C

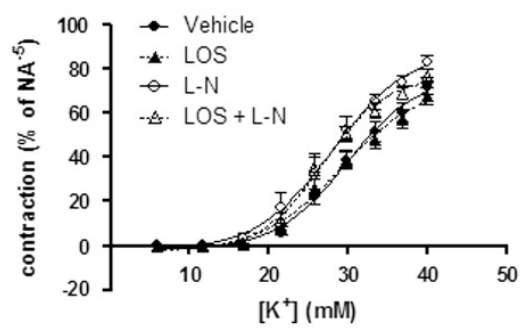

d

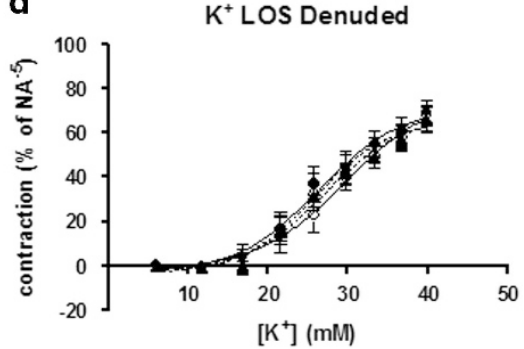

e
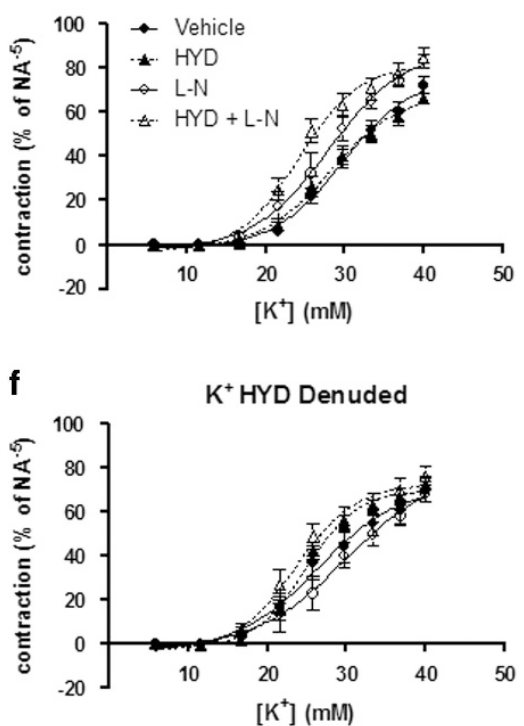

Figure $1 \mathrm{~K}^{+}$-induced contractile responses in intact ( $\left.\mathbf{a}, \mathbf{c}, \mathbf{e}\right)$ and denuded (b, $\left.\mathbf{d}, \mathbf{f}\right)$ arteries in presence of vehicle (all panels, solid lines and closed circles), SOL1 ( $\mathbf{a}$ and $\mathbf{b}$, dotted lines and closed triangles), losartan ( $\mathbf{c}$ and $\mathbf{d}$, dotted lines and closed triangles) or hydralazine (c and $\mathbf{d}$, dotted lines and closed triangles). Open symbols: in the presence of L-NAME (L-N).

SOL1 and hydralazine groups and was significantly decreased in the losartan group (Table 1). Optimal diameter of third-order mesenteric resistance arteries was reduced by chronic treatment with losartan but was not affected by the other drugs. The cross-sectional area of the media and media-to-lumen ratio of third-order mesenteric resistance arteries were comparable in vehicle-, SOL1-, losartan- and hydralazine-treated animals. The maximal contractile response to NA was not altered in the losartan and hydralazine groups and tended to be increased in the SOL1-treated group (Table 1).

Effects of chronic treatments on $\mathrm{K}^{+}$-induced arterial contractions In third-order mesenteric arteries, the $\mathrm{pEC}_{50}$ and $E_{\max }$ of $\mathrm{K}^{+}$-induced contraction did not differ between treatment groups (Figure 1, Table 2). L-NAME did not modify the $\mathrm{pEC}_{50}$ but increased $E_{\max }$ in all groups (saline: $72.3 \pm 3.8 \%$ to $83.3 \pm 3.0 \%$; SOL1: $61.7 \pm 5.5 \%$ to $78.9 \pm 4.4 \%$; losartan: $67.9 \pm 4.1 \%$ to $77.3 \pm 3.0 \%$; hydralazine: $66.3 \pm 2.2 \%$ to $84.7 \pm 4.8 \%$ ).

Endothelial denudation or bosentan $\left(10 \mu \mathrm{M}\right.$, non-selective $\mathrm{ET}_{\mathrm{A} / \mathrm{B}}$ antagonist) did not alter $\mathrm{K}^{+}$-induced contractile responses (Table 2).
In denuded arteries in all four treatment groups, L-NAME did not increase $\mathrm{K}^{+}$-induced contractions either (Figure 1, Table 2).

\section{Effects of chronic treatments on phenylephrine-induced contractile responses}

Sensitivity to PHE was significantly reduced by treatment with SOL1 or losartan $\left(\mathrm{pEC}_{50}\right.$, vehicle: $5.69 \pm 0.03$, SOL1: $5.53 \pm 0.02$; losartan: $5.50 \pm 0.05$ ) but was increased by treatment with hydralazine ( $\mathrm{pEC}_{50}$ : hydralazine: $5.90 \pm 0.03$ ). L-NAME significantly increased the sensitivity to PHE in intact arteries of SOL1-treated animals $(5.75 \pm 0.02)$ but had no effect in arteries from vehicle-, losartan- or hydralazine-treated groups. Similarly, mechanical removal of the endothelium increased the sensitivity to PHE in SOL1-treated animals $\left(\mathrm{pEC}_{50}: 5.68 \pm 0.07\right)$ but not in the vehicle-, losartan- or hydralazine-treated groups. L-NAME had no effects in denuded arteries (Figure 2, Table 3).

Bosentan decreased the sensitivity to PHE in arteries of SOL1-treated SHR in absence and presence of L-NAME (-L-NAME: $5.35 \pm 0.03$; +L-NAME: $5.65 \pm 0.02)$. No effects of bosentan on 
Table $2 \mathrm{pEC}_{50}$ and $E_{\max }$ of contractile responses to increasing concentrations of $\mathrm{K}^{+}$

\begin{tabular}{|c|c|c|c|c|}
\hline & Vehicle & $S O L-1$ & Losartan & Hydralazine \\
\hline \multicolumn{5}{|l|}{ Control } \\
\hline $\mathrm{pEC}_{50}$ & $1.52 \pm 0.03$ & $1.43 \pm 0.10$ & $1.52 \pm 0.03$ & $1.53 \pm 0.03$ \\
\hline \multicolumn{5}{|l|}{$+\angle-N A M E$} \\
\hline $\mathrm{pEC}_{50}$ & $1.55 \pm 0.02$ & $1.53 \pm 0.02$ & $1.57 \pm 0.01$ & $1.60 \pm 0.01$ \\
\hline
\end{tabular}

Abbreviation: NA, noradrenaline.

Amplitude of contraction is expressed as \% of the maximal response to NA. Results are shown as mean \pm s.e.m.

a $P<0.05$ without $v s$. with $L-N A M E$.

a

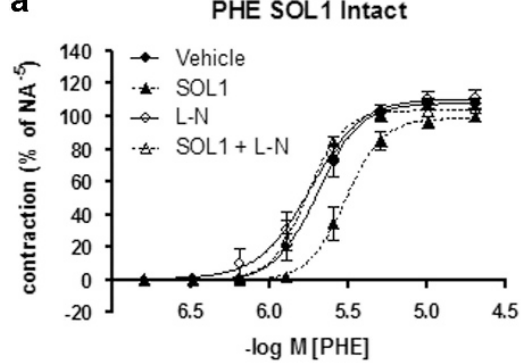

b

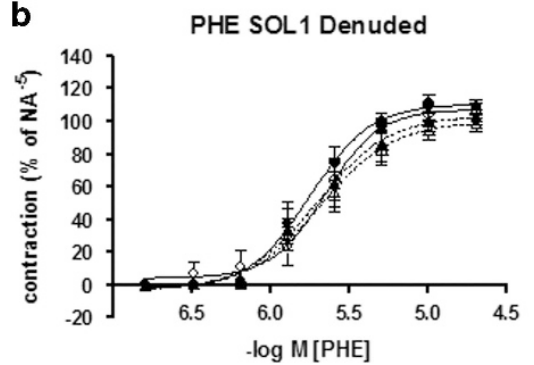

C

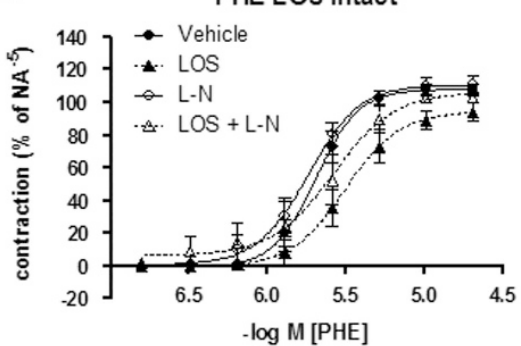

d

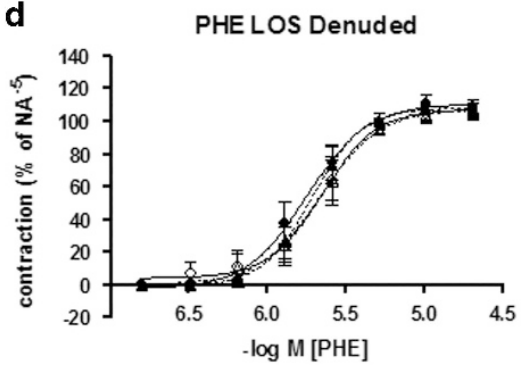

e

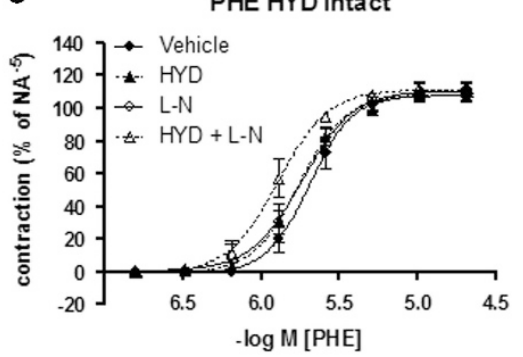

f

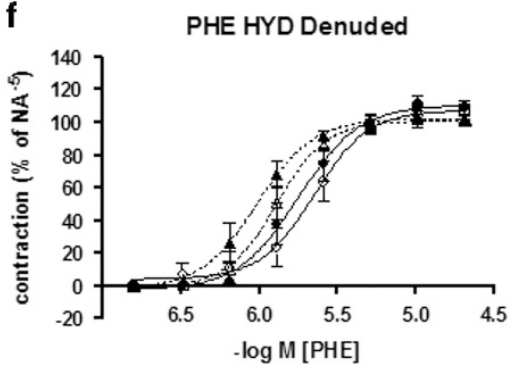

Figure 2 Contractile responses to PHE in intact (a, c, e) and denuded (b, d, f) arteries with vehicle (all panels, solid lines and closed circles), SOL1 (a and $\mathbf{b}$, dotted lines and closed triangles), losartan (c and $\mathbf{d}$, dotted lines and closed triangles) or hydralazine (c and $\mathbf{d}$, dotted lines and closed triangles). Open symbols: in presence of L-NAME $(\mathrm{L}-\mathrm{N})$.

Table $3 \mathrm{pEC}_{50}$ and $E_{\max }$ as measured during PHE-induced contractile responses

\begin{tabular}{lcccc}
\hline & Vehicle & SOL-1 & Losartan & Hydralazine \\
\hline Control & & & & \\
$\mathrm{pEC}_{50}$ & $5.69 \pm 0.02$ & $5.54 \pm 0.03^{\mathrm{a}}$ & $5.50 \pm 0.05^{\mathrm{a}}$ & $5.90 \pm 0.03^{\mathrm{a}}$ \\
$E_{\max }(\%)$ & $107.9 \pm 3.5$ & $100.3 \pm 3.2$ & $94.3 \pm 5.3$ & $110.9 \pm 2.7$ \\
& & & & \\
+ L-NAME & & & & \\
$\mathrm{pEC} C_{50}$ & $5.71 \pm 0.04$ & $5.75 \pm 0.02^{\mathrm{b}}$ & $5.58 \pm 0.08$ & $5.75 \pm 0.02$ \\
$E_{\max }(\%)$ & $111.0 \pm 5.5$ & $105.4 \pm 3.2$ & $103.0 \pm 3.3$ & $112.0 \pm 3.3$
\end{tabular}

Results are depicted as mean \pm s.e.m.

a $P<0.05$ treatment vs. Vehicle.

${ }^{b} P<0.05$ without $v s$. with L-NAME.

PHE-induced contractile responses were observed in the vehicle-, losartan- or hydralazine-treated groups. Maximal responses to PHE were not modified by the chronic drug treatments and were not altered by L-NAME, bosentan or endothelium removal (Figure 2, Table 3).
Effects of chronic NEP/ECE inhibition and anti-hypertensive treatments on arterial responses to acetylcholine

To assess endothelium-dependent responses, arteries were contracted with PHE and exposed to increasing concentrations of ACh (0.001-10 $\mu \mathrm{M})$. In third-order mesenteric resistance arteries of 32-week-old SHR, $\mathrm{pEC}_{50}$ and $E_{\max }$ to ACh-induced relaxations did not differ significantly between treatment groups (Figure 3a). Notably, $E_{\max }$ tended to be decreased by chronic hydralazine treatment and tended to be increased by chronic losartan and SOL1 treatment. Maximal responses to ACh were not modified by acute bosentan administration (slight increase; Figure $3 \mathrm{a}$ and $\mathrm{b}$ ). However, $E_{\max }$ to ACh-induced relaxations were significantly increased in all groups by acute INDO administration (Figure $3 \mathrm{a}-\mathrm{d}$ ). This effect is due to reduction by the COX inhibitor of the contractile response that is observed with high concentrations of ACh.

Effects of chronic NEP/ECE inhibition and anti-hypertensive treatments on EDHF-related arterial responses

To assess the contribution of EDHF to ACh (0.001-10 $\mu \mathrm{M})$ induced relaxing responses, arteries were contracted with PHE $(20 \mu \mathrm{M})$ in presence of INDO (to prevent formation of vasodilator and 
a

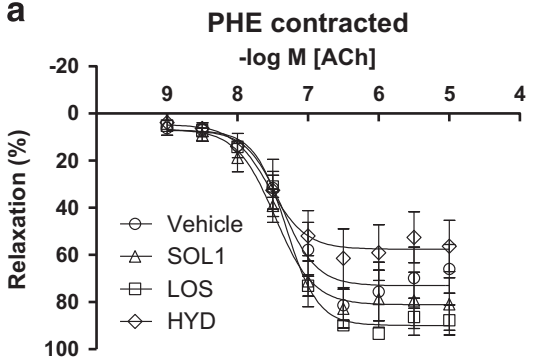

C PHE contracted + INDO

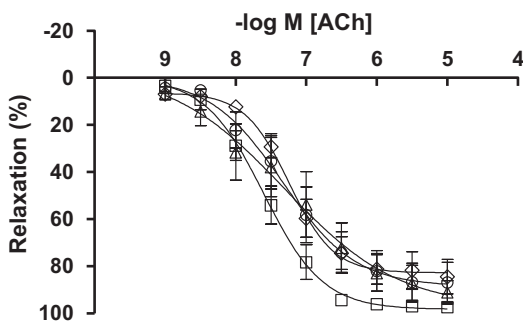

e PHE contracted + INDO + L-NAME

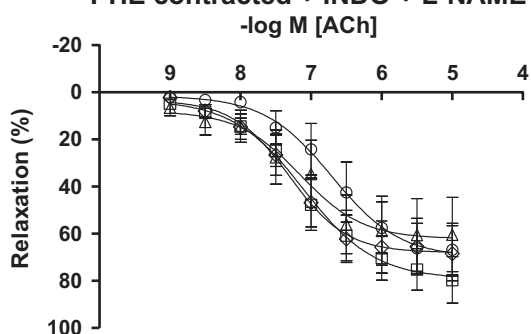

$9 \quad \mathrm{~K}^{+}$contracted + INDO

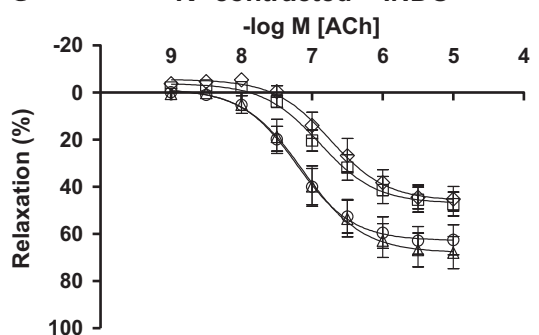

b

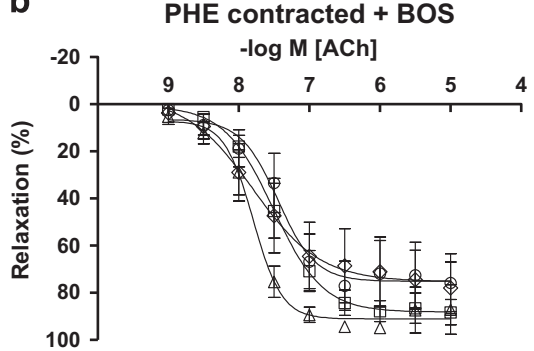

d

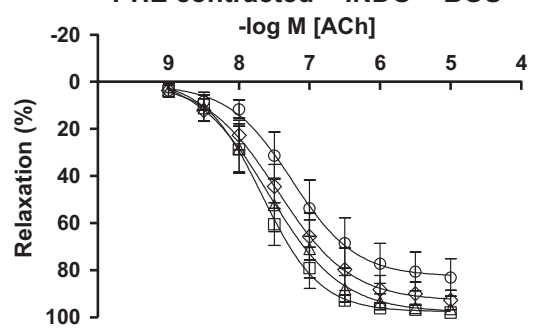

f PHE contracted + INDO + L-NAME + BOS

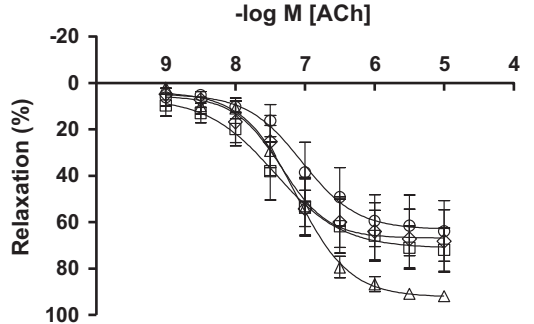

h

$\mathrm{K}^{+}$contracted + INDO + BOS $-\log \mathrm{M}[\mathrm{ACh}]$

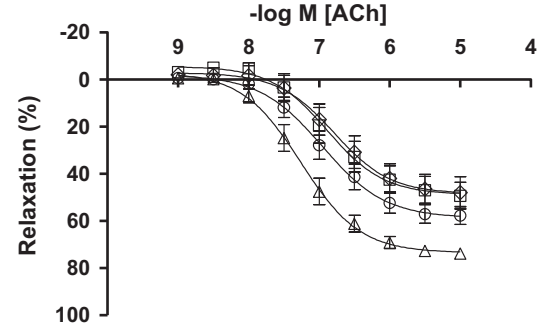

Figure 3 Relaxing responses of mesenteric resistance arteries of SHR to ACh in absence or presence of INDO. The top panels depict responses in absence and presence of INDO and absence (a, c) and presence (b, d) of bosentan (BOS) with vehicle (open circles), SOL1 (open triangles), losartan (open squares) or hydralazine (open diamonds). The middle panels depict responses to ACh during PHE-induced contractions in presence of INDO and L-NAME (EDHF-related responses) in absence (e) and presence ( $\mathbf{f}$ ) of BOS. The bottom panels depict responses to ACh during $\mathrm{K}^{+}$-induced contraction in presence of INDO, in absence (g) and presence (h) of BOS (EDNO-related responses). EDHF, endothelium-derived hyperpolarizing factor; EDNO, endothelium-derived nitric oxide; INDO, indomethacin; PHE, phenylephrine.

vasoconstrictor prostaglandins) and L-NAME (to prevent involvement of $\mathrm{NO}$ ). Obviously, the remaining ACh-induced response was mediated by EDHF.

Sensitivity and maximal response did not differ significantly between groups. Bosentan significantly increased maximal EDHF-type responses in the SOL1-treated animals $(57.0 \pm 13.1 \%$ to $91.9 \pm 2.0 \%$ ) but not in the vehicle-, losartan- or hydralazine-treated animals. In the presence of bosentan, maximal EDHF-type responses were significantly larger in the SOL1-treated animals compared to vehicle $(63.9 \pm 13.1 \%$ to $91.9 \pm 2.0 \%$; Figure $3 \mathrm{e}$ and $\mathrm{f}$; Table 4).
Effects of chronic NEP/ECE inhibition and anti-hypertensive treatments on arterial responses to endothelium-derived NO To investigate the contribution of NO to ACh-induced $(0.001-10 \mu \mathrm{M})$ relaxing responses, arteries contracted with $40 \mathrm{Mm} \mathrm{K}^{+}$in the presence of INDO (to prevent formation of vasodilator and vasoconstrictor prostaglandins). A high extracellular $\mathrm{K}^{+}$concentration effectively prevents EDHF-related responses. ${ }^{28}$ The remaining ACh-induced response was abolished in the presence of L-NAME and was thus considered to be due to endothelium-derived NO (EDNO). Sensitivity and maximal responses did not differ significantly between groups. The maximal ACh-induced EDNO response in presence of bosentan 
Table $4 \mathrm{pEC}_{50}$ and $E_{\max }$ of the relaxing response induced by increasing concentrations of $\mathrm{ACh}$

\begin{tabular}{cllll}
\hline & Vehicle & SOL1 & Losartan & Hydralazine \\
\hline EDNO & & & & \\
$\quad$ Control & & & & \\
$\quad \mathrm{pEC} \mathrm{C}_{50}$ & $7.18 \pm 0.15$ & $7.11 \pm 0.18$ & $6.89 \pm 0.12$ & $6.71 \pm 0.13$ \\
$\quad E_{\max }(\%)$ & $62.6 \pm 6.4$ & $68.0 \pm 6.8$ & $47.4 \pm 5.1$ & $45.1 \pm 5.2$ \\
Bosentan & & & & \\
$\quad \mathrm{pEC} C_{50}$ & $6.95 \pm 0.11$ & $7.22 \pm 0.08$ & $6.88 \pm 0.15$ & $6.78 \pm 0.20$ \\
$E_{\max }(\%)$ & $58.4 \pm 4.3$ & $71.0 \pm 3.4^{\mathrm{a}}$ & $49.4 \pm 5.7$ & $48.0 \pm 6.7$ \\
& & & & \\
EDHF & & & & \\
Control & & & & \\
$\quad \mathrm{pEC} C_{50}$ & $6.72 \pm 0.28$ & $7.14 \pm 0.39$ & $7.04 \pm 0.19$ & $7.31 \pm 0.25$ \\
$E_{\max }(\%)$ & $66.9 \pm 11.2$ & $60.43 \pm 15.8$ & $79.8 \pm 8.9$ & $68.4 \pm 11.7$ \\
Bosentan & & & & \\
$\quad$ Log EC $C_{50}$ & $7.04 \pm 0.27$ & $7.13 \pm 0.10$ & $7.43 \pm 0.31$ & $7.31 \pm 0.25$ \\
$E_{\max }(\%)$ & $63.9 \pm 13.1$ & $91.86 \pm 2.0^{\mathrm{a}}$ & $71.9 \pm 9.4$ & $68.1 \pm 13.1$ \\
\hline
\end{tabular}

Abbreviations: EDHF, endothelium-derived hyperpolarizing factor (precontraction with $20 \mu \mathrm{M}$ PHE in presence of L-NAME); EDNO, endothelium-derived nitric oxide (precontraction with PHE in presenc 40 mM $\mathrm{K}^{+}$).

$\left.40 \mathrm{~mm} \mathrm{~K}^{+}\right)$.

Results are depicted as mean \pm s.e.m.

${ }^{a} P<0.05$ treatment vs. Vehicle.

was increased in SOL1-treated animals vs. vehicle-treated animals $(58.4 \pm 4.2 \%$ to $71.0 \pm 3.4 \%)$ and was unaltered in losartan- or hydralazine-treated groups (Figure $3 \mathrm{~g}$ and h; Table 4 ).

\section{DISCUSSION}

This study demonstrates that chronic SOL1 treatment can restore several aspects of endothelial function, even though an effect on blood pressure was minimal. In contrast, more classic antihypertensive drugs, such as losartan or hydralazine, were both effective in lowering blood pressure but had little to no effect on endothelial dysfunction, even though losartan succeeded in partly reversing the resistance artery structural changes associated with hypertension.

ET-1 is involved in the pathophysiology of experimental and clinical pulmonary hypertension, chronic renal failure and heart failure. The situation in essential hypertension is, however, less clear. ${ }^{29}$ In SHR, the role of the renin-angiotensin system is well established. ${ }^{30} \mathrm{~A}$ potential role of the endothelin system in the arterial functional and structural changes is, however, less clear. ${ }^{31}$ Montagnani et al. ${ }^{32}$ reported that while there is no difference in ET-1-induced contractions between 5-week-old SHR and Wister Kyoto rats, they noted a marked increase in ET-1-induced contractile responses in 12-week-old SHR. Furthermore, our group reported increased levels of ET-1 in several organs of 8- and 12-week-old SHR. ${ }^{11}$ This points to a transient upregulation of the endothelin system during the development of hypertension. ET-1 is not only a very potent vasoconstrictor ${ }^{12}$ but is also a proinflammatory agent, ${ }^{15}$ has mitogenic effects on vascular smooth muscle cells, ${ }^{13}$ is pro-angiogenic, ${ }^{16}$ pro-oxidant $^{33}$ and promotes fibrosis. ${ }^{14}$ Moreover, endothelium restricted overexpression of ET-1 causes vascular remodeling and endothelial dysfunction in the absence of a hemodynamic effect. ${ }^{33}$ The pro-oxidant and pro-inflammatory functions might, at least in some forms of hypertension, be more important than the pressor effect. Because of the aforementioned functions, the ET-1 system emerges as a potential target for normalizing functional and structural arterial properties that are associated with hypertension.
We tested the hypothesis that ET-1 contributes to endothelial dysfunction, arterial remodeling and hypertension in 32-week-old SHR. To evaluate this, we treated adult SHR with the dual NEP/ECE inhibitor SOL1, which effectively decreases big-ET-1 to ET-1 conversion, ${ }^{34}$ and compared the effects with a 4 -week treatment with an $\mathrm{AT}_{1}$ receptor antagonist (losartan) and a 4-week treatment with a vasodilator (hydralazine). Decreasing ET-1 production might be helpful in conditions where either the intravascular levels of ET-1 and/or the vascular effects of the peptide are increased..$^{32,35-37}$ Moreover, inhibiting NEP might have added beneficial value by chronically inhibiting the breakdown of other vasoactive peptides, such as natriuretic peptides and calcitonin gene-related peptide. ${ }^{38-41} \mathrm{We}$ investigated both structural and functional effects of SOL1 in mesenteric resistance arteries.

ET-1 has been shown to contribute to remodeling of large and small arteries in hypertension. Hypertrophic remodeling rather than eutrophic remodeling of resistance arteries, seems to occur in models associated with an upregulated ET system suggesting that ET-1 system upregulation leads to vascular hypertrophy. ${ }^{42}$

In the current study, we observed no significant change in diameter, media thickness, cross-sectional area of the media, nuclear cell count or media-to-lumen ratio in first-order mesenteric resistance arteries of 32week-old SHR caused by reducing blood pressure by means of a 4 -week treatment with a vasodilator (hydralazine). This means that a decrease in blood pressure alone cannot reverse structural changes in these arteries. These observations are consistent with earlier reports. ${ }^{43-45}$

Chronic losartan treatment did not cause a significant increase in diameter or a decrease in cross-sectional area of the media or, the nuclear cell count in first-order mesenteric arteries of SHR. These arteries do, however, show a decrease in media-to-lumen ratio. Despite differences in experimental design and treatment timing, our findings are similar to earlier reports from other groups. ${ }^{8,43,44,46}$ Studies with chronic $\mathrm{AT}_{1}$ receptor antagonists have shown that treatment for a longer period than 4 weeks is superior for establishing beneficial effects on vascular remodeling. ${ }^{47}$

In contrast to chronic losartan treatment, SOL1 treatment was not successful in reducing blood pressure or arterial structural changes. The absence of an anti-hypertensive effect is consistent with observations made by Kalk et al. ${ }^{48}$, who did not observe a blood pressure reduction with daglutril (SLV338; a SOL1 analog) ${ }^{21}$ in the 2-kidney 1-clip model. Similarly, Sharkovska et al. did not observe a blood pressure reduction with daglutril in rats chronically treated with L-NAME. In addition, as with losartan, a 4-week treatment with the NEP/ECE inhibitor might have been too short to fully correct structural changes in resistance arteries.

To assess arterial and endothelial function and the effects of a chronic SOL1 treatment, we investigated third-order mesenteric resistance arteries in vitro. Functional properties of resistance-sized arteries are often altered in hypertension in relation to dysfunctional endothelium. Endothelial dysfunction is frequently regarded as a reduced bioavailability or function of EDNO, blunted EDHF responses and hypersensitivity to vasoconstrictors. ${ }^{49}$ In SHR, specifically EDCFs are described as a manifestation of endothelial dysfunction and these EDCFmediated contractions in response to stimulation of the artery with ACh are fully inhibited by a cyclo-oxygenase inhibitor (INDO). In 32-weekold SHR investigated in this study, a moderate EDCF component was observed. The prostanoids $\mathrm{PGH}_{2}, \mathrm{PGI}_{2}$ and thromboxane $\mathrm{A}_{2}\left(\mathrm{TXA}_{2}\right)$ have been suggested to be responsible for increased vascular tone in hypertension. ${ }^{50}$ Recently, Spijkers et al. reported endothelium-dependent contractions as a result of increased $\mathrm{TXA}_{2}$ release in arteries of SHR. Moreover, they observed an increased expression of COX-1 in smooth 
muscle cells of SHR compared to Wister Kyoto rats and an increased expression of $\mathrm{PLA}_{2}$ (substrate delivery to COX-1) and $\mathrm{TXA}_{2}$-synthase in the endothelium of SHR compared to Wister Kyoto rats. ${ }^{22,51}$ In the present study, the EDCF response (indicated by a reduced maximal relaxing response to $\mathrm{ACh}$ ) was abolished by cyclo-oxygenase inhibition and moderately inhibited by acute ET-receptor antagonism and by chronic losartan or SOL1 treatment.

No effects of hydralazine, losartan or SOL1 were observed on arterial smooth contractile responses to $\mathrm{K}^{+}$-induced depolarization. Sensitivity to smooth muscle activation was similar in all groups. Except for the hydralazine-treated animals, there was no effect of L-NAME on $\mathrm{pEC}_{50}$ or $E_{\max }$. Normally, NO synthase inhibition causes a leftward shift in the concentration-response curve and an increased maximal response. ${ }^{52}$ These effects are absent in the arteries investigated in this study, meaning that the NO production under basal conditions (for example, without agonist-induced stimulation) is blunted. None of the treatments could restore the L-NAME induced leftward shift and only hydralazine restored the increase in maximal contraction induced by L-NAME.

A similar L-NAME-induced leftward shift can be expected for PHE-induced concentration-response curves. ${ }^{25,52}$ Again, this shift was completely absent in vehicle-, losartan- or hydralazine-treated groups. After 4 weeks of chronic dual NEP/ECE inhibition, however, L-NAME caused a significant leftward shift. This can be considered an improvement of basal endothelial function because to some extent chronic SOL1 treatment succeeds in restoring basal NO production. The molecular mechanism of this effect of a 4-week treatment with the NEP/ECE inhibitor might involve changes in the dimerization and phosphorylation of endothelial NO synthase, but this remains to be established. ${ }^{53}$

In this study, the agonist-induced EDNO-type responses were not significantly altered by any of the chronic treatments. Surprisingly, acute administration of the non-selective $\mathrm{ET}_{\mathrm{A} / \mathrm{B}}$ receptor antagonist bosentan improved the maximal EDNO-type responses in SOL1treated animals. This might indicate that intra-arterial production of ET-1 is rapidly restored in vitro after wash-out of the ECE/NEP inhibitor that had been administered for 4 weeks. Another EDRF, EDHF causes endothelial hyperpolarization with subsequent vascular smooth muscle cell hyperpolarization. The contribution of EDHF is most marked in small arteries. ${ }^{24,54}$ In mesenteric resistance arteries, this response is blocked by depolarization with high extracellular $\left[\mathrm{K}^{+}\right]$ or inhibitors of endothelial small- and intermediate-conductance calcium-activated $\mathrm{K}^{+}$channels. ${ }^{24,28,55,56}$ EDHF-type responses were not significantly affected by SOL1, losartan or hydralazine treatment. Acute administration of the non-selective $\mathrm{ET}_{\mathrm{A} / \mathrm{B}}$ receptor antagonist bosentan improved the maximal EDHF-type relaxing responses in SOL1-treated animals. This means that both EDNO- and EDHF-type responses in the SOL1-treated group were improved by acute ET-receptor antagonism. Because SOL1 is easily removed from organs, ${ }^{20}$ conversion of big-ET-1 to ET-1 may recommence before endothelial function is investigated. Subsequently, ET-1 might impair endothelium-derived relaxing responses through a similar myo-endothelial coupling mechanism, as proposed by Hilgers and De Mey. ${ }^{25}$ This might explain the acute bosentan effect on the EDHF response in the SOL1-treated animals.

In conclusion, chronic treatment with an $\mathrm{AT}_{1}$ receptor antagonist in 32-week-old SHR caused regression of the changes in arterial structure and a significant lowering of the blood pressure. Chronic dual NEP/ECE inhibition, on the other hand, caused an improvement of several aspects of endothelial function. While the effects of losartan and SOL1 are different, they could be considered beneficial in both instances. A combination of an $\mathrm{AT}_{1}$ receptor antagonist, or alternatively an inhibitor of angiotensin converting enzyme (ACE), with a dual NEP/ECE inhibitor could provide superior results and might be subject of future studies. Triple vasopeptidase (ACE/ECE/NEP) inhibitors are becoming available (for review, Duall et al. ${ }^{57}$ ) and deserve detailed investigation in terms of anti-hypertensive effects and restoration of structural and endothelial properties in resistance arteries.

\section{CONFLICT OF INTEREST}

The authors declare no conflict of interest.

\section{ACKNOWLEDGEMENTS}

This study was performed within the framework of the Dutch Top Institute Pharma project: T2-108; Metalloproteases and Novel Targets in Endothelial Dysfunction.

1 Furchgott RF, Vanhoutte PM. Endothelium-derived relaxing and contracting factors. FASEB J 1989; 3: 2007-2018.

2 Feletou M, Vanhoutte PM. Endothelium-derived hyperpolarizing factor: where are we now? Arterioscler Thromb Vasc Biol 2006; 26: 1215-1225.

3 Tang EH, Vanhoutte PM. Endothelial dysfunction: a strategic target in the treatment of hypertension? Pflugers Arch 2010; 459: 995-1004.

4 Vanhoutte PM, Shimokawa H, Tang EH, Feletou M. Endothelial dysfunction and vascular disease. Acta Physiol 2009; 196: 193-222.

5 Heagerty AM, Aalkjaer C, Bund SJ, Korsgaard N, Mulvany MJ. Small artery structure in hypertension. Dual processes of remodeling and growth. Hypertension 1993; 21: 391-397.

6 Gluais P, Lonchampt M, Morrow JD, Vanhoutte PM, Feletou M. Acetylcholine-induced endothelium-dependent contractions in the SHR aorta: the Janus face of prostacyclin. Br J Pharmacol 2005; 146: 834-845.

7 Smith RD, Yokoyama H, Averill DB, Schiffrin EL, Ferrario CM. Reversal of vascular hypertrophy in hypertensive patients through blockade of angiotensin II receptors. J Am Soc Hypertens 2008; 2: 165-172.

8 Schiffrin EL, Park JB, Intengan HD, Touyz RM. Correction of arterial structure and endothelial dysfunction in human essential hypertension by the angiotensin receptor antagonist losartan. Circulation 2000; 101: 1653-1659.

9 Thybo NK, Stephens N, Cooper A, Aalkjaer C, Heagerty AM, Mulvany MJ. Effect of antihypertensive treatment on small arteries of patients with previously untreated essential hypertension. Hypertension 1995; 25: 474-481.

10 Schiffrin EL, Deng LY, Larochelle P. Progressive improvement in the structure of resistance arteries of hypertensive patients after 2 years of treatment with an angiotensin l-converting enzyme inhibitor. Comparison with effects of a beta-blocker. Am J Hypertens 1995; 8: 229-236.

11 Nelissen J, Heijnen B, Lemkens P, Debets J, van Essen H, Bost J, Schiffers P, De Mey J, Janssen B. Endothelin-1 and Calcitonin Gene-Related Peptide contribute to the developing hypertension in young spontaneously hypertensive rats. FASEB J 2011; 25. Supplement 823.2.

12 Yanagisawa M, Kurihara H, Kimura S, Tomobe Y, Kobayashi M, Mitsui Y, Yazaki Y, Goto $\mathrm{K}$, Masaki T. A novel potent vasoconstrictor peptide produced by vascular endothelial cells. Nature 1988; 332: 411-415.

13 Donckier JE, Michel L, Van Beneden R, Delos M, Havaux X. Increased expression of endothelin-1 and its mitogenic receptor ETA in human papillary thyroid carcinoma. Clin Endocrinol 2003; 59: 354-360.

14 Ammarguellat F, Larouche I, Schiffrin EL. Myocardial fibrosis in DOCA-salt hypertensive rats: effect of endothelin ET(A) receptor antagonism. Circulation 2001; 103: 319-324.

15 Saleh MA, Boesen EI, Pollock JS, Savin VJ, Pollock DM. Endothelin-1 increases glomerular permeability and inflammation independent of blood pressure in the rat. Hypertension 2010; 56: 942-949.

16 Boldrini L, Pistolesi S, Gisfredi S, Ursino S, Ali G, Pieracci N, Basolo F, Parenti G, Fontanini G. Expression of endothelin 1 and its angiogenic role in meningiomas. Virchows Arch 2006; 449: 546-553.

17 Sawamura T, Kimura S, Shinmi O, Sugita Y, Yanagisawa M, Goto K, Masaki T. Purification and characterization of putative endothelin converting enzyme in bovine adrenal medulla: evidence for a cathepsin D-like enzyme. Biochem Biophys Res Commun 1990; 168: 1230-1236.

18 Nakano A, Kishi F, Minami K, Wakabayashi H, Nakaya Y, Kido H. Selective conversion of big endothelins to tracheal smooth muscle-constricting 31-amino acid-length endothelins by chymase from human mast cells. J Immunol 1997; 159: 1987-1992.

19 Fernandez-Patron C, Radomski MW, Davidge ST. Vascular matrix metalloproteinase-2 cleaves big endothelin-1 yielding a novel vasoconstrictor. Circ Res 1999; 85: 906-911.

20 Nelissen J, Lemkens P, Sann H, Bindl M, Bassissi F, Jasserand D, De Mey JG, Janssen BJ. Pharmacokinetic and pharmacodynamic properties of SOL1: a novel dual inhibitor 
of neutral endopeptidase and endothelin converting enzyme. Life Sci 2012; 91: 587-592.

21 Kalk P, Sharkovska Y, Kashina E, von Websky K, Relle K, Pfab T, Alter M, Guillaume P, Provost D, Hoffmann K, Fischer Y, Hocher B. Endothelin-converting enzyme/neutral endopeptidase inhibitor SLV338 prevents hypertensive cardiac remodeling in a blood pressure-independent manner. Hypertension 2011; 57: 755-763.

22 Spijkers LJ, Janssen BJ, Nelissen J, Meens MJ, Wijesinghe D, Chalfant CE, De Mey JG, Alewijnse AE, Peters SL. Antihypertensive treatment differentially affects vascular sphingolipid biology in spontaneously hypertensive rats. PLOS ONE 2011; 6: e29222.

23 Pourageaud F, De Mey JG. Structural properties of rat mesenteric small arteries after 4-wk exposure to elevated or reduced blood flow. Am J Physiol 1997; 273: H1699-H1706.

24 Hilgers RH, Todd J Jr., Webb RC. Regional heterogeneity in acetylcholine-induced relaxation in rat vascular bed: role of calcium-activated $\mathrm{K}+$ channels. Am J Physiol Heart Circ Physiol 2006; 291: H216-H222.

25 Hilgers RH, De Mey JG. Myoendothelial coupling in the mesenteric arterial bed; segmental differences and interplay between nitric oxide and endothelin-1. $\mathrm{Br} J$ Pharmacol 2009; 156: 1239-1247.

26 Wang Y, Wang DH. Prevention of endothelin-1-induced increases in blood pressure: role of endogenous CGRP. Am J Physiol Heart Circ Physiol 2004; 287: H1868-H1874.

27 De Mey JG, Megens R, Fazzi GE. Functional antagonism between endogenous neuropeptide $\mathrm{Y}$ and calcitonin gene-related peptide in mesenteric resistance arteries. J Pharmacol Exp Ther 2008; 324: 930-937.

28 Adeagbo AS, Triggle CR. Varying extracellular [K+]: a functional approach to separating EDHF- and EDNO-related mechanisms in perfused rat mesenteric arterial bed. J Cardiovasc Pharmacol 1993; 21: 423-429.

29 Davenport AP, Hyndman KA, Dhaun N, Southan C, Kohan DE, Pollock JS, Pollock DM, Webb DJ, Maguire JJ. Endothelin. Pharmacol Rev 2016; 68: 357-418.

30 Rizzoni D, Porteri E, Piccoli A, Castellano M, Bettoni G, Muiesan ML, Pasini G, Guelfi D, Mulvany MJ, Agabiti Rosei E. Effects of losartan and enalapril on small artery structure in hypertensive rats. Hypertension 1998; 32: 305-310.

31 Schiffrin EL. Vascular endothelin in hypertension. Vascul Pharmacol 2005; 43: 19-29.

32 Montagnani M, Vulpis V, Nazzaro P, Potenza MA, Rinaldi R, Nacci C, De Salvia MA, Siro Brigiani G, Pirrelli A, Mitolo-Chieppa D. Endothelin-1-receptor-mediated responses in resistance vessels of young and adult spontaneously hypertensive rats. J Hypertens 2000; 18: 893-900.

33 Amiri F, Virdis A, Neves MF, Iglarz M, Seidah NG, Touyz RM, Reudelhuber TL, Schiffrin EL. Endothelium-restricted overexpression of human endothelin-1 causes vascular remodeling and endothelial dysfunction. Circulation 2004; 110: 2233-2240.

34 Nelissen J, Lemkens P, Sann H, Bindl M, Bassissi F, Jasserand D, De Mey JG, Janssen BJ. Pharmacokinetic and pharmacodynamic properties of SOL1: A novel dual inhibitor of neutral endopeptidase and endothelin converting enzyme. Life Sci 2012; 91: 587-592.

35 Touyz RM, Lariviere R, Schiffrin EL. Endothelin receptor subtypes in mesenteric vascular smooth muscle cells of spontaneously hypertensive rats. Can J Physiol Pharmacol 1995; 73: 1262-1273.

36 Dohi Y, Hahn AW, Boulanger CM, Buhler FR, Luscher TF. Endothelin stimulated by angiotensin II augments contractility of spontaneously hypertensive rat resistance arteries. Hypertension 1992; 19: 131-137.

37 Akter S, Jesmin S, Iwashima Y, Hideaki S, Rahman MA, Islam MM, Moroi M, Shimojo N, Yamaguchi N, Miyauchi T, Kawano S, Mizutani T, Kawano Y. Higher circulatory level of endothelin-1 in hypertensive subjects screened through a cross-sectional study of rural Bangladeshi women. Hypertens Res 2015; 38: 208-212.

38 Kenny AJ, Bourne A, Ingram J. Hydrolysis of human and pig brain natriuretic peptides, urodilatin, C-type natriuretic peptide and some $\mathrm{C}$-receptor ligands by endopeptidase24.11. Biochem J 1993; 291: 83-88.
39 Yandle TG, Brennan SO, Espiner EA, Nicholls MG, Richards AM. Endopeptidase-24.11 in human plasma degrades atrial natriuretic factor (ANF) to ANF(99-105/106-126). Peptides 1989; 10: 891-894.

40 Katayama M, Nadel JA, Bunnett NW, Di Maria GU, Haxhiu M, Borson DB. Catabolism of calcitonin gene-related peptide and substance $\mathrm{P}$ by neutral endopeptidase. Peptides 1991; 12: 563-567.

41 Ito S, Satoh M, Tamaki Y, Gotou H, Charney A, Okino N, Akahori M, Zhang J. Safety and efficacy of LCZ696, a first-in-class angiotensin receptor neprilysin inhibitor, in Japanese patients with hypertension and renal dysfunction. Hypertens Res 2015; 38 : 269-275.

42 Li JS, Lariviere R, Schiffrin EL. Effect of a nonselective endothelin antagonist on vascular remodeling in deoxycorticosterone acetate-salt hypertensive rats. Evidence for a role of endothelin in vascular hypertrophy. Hypertension 1994; 24: 183-188.

43 Soltis EE. Alterations in vascular structure and function after short-term losartan treatment in spontaneously hypertensive rats. J Pharmacol Exp Ther 1993; 266: 642-646.

44 Pu Q, Brassard P, Javeshghani DM, Iglarz M, Webb RL, Amiri F, Schiffrin EL. Effects of combined AT1 receptor antagonist/NEP inhibitor on vascular remodeling and cardiac fibrosis in SHRSP. J Hypertens 2008; 26: 322-333.

45 Eerdmans PH, Struyker Boudier HA, De Mey JG. Contractile reactivity of isolated resistance arteries after 4 weeks of treatment with rilmenidine, clonidine or hydralazine in spontaneously hypertensive rats. J Hypertens Supp/ 1991; 9: S348-S349.

46 Morton JJ, Beattie EC, MacPherson F. Angiotensin II receptor antagonist losartan has persistent effects on blood pressure in the young spontaneously hypertensive rat: lack of relation to vascular structure. J Vasc Res 1992; 29: 264-269.

47 de Cavanagh EM, Ferder LF, Ferder MD, Stella IY, Toblli JE, Inserra F. Vascular structure and oxidative stress in salt-loaded spontaneously hypertensive rats: effects of losartan and atenolol. Am J Hypertens 2010; 23: 1318-1325.

48 Sharkovska Y, Kalk P, von Websky K, Relle K, Pfab T, Alter M, Fischer Y, Hocher B. Renoprotective effects of combined endothelin-converting enzyme/neutral endopeptidase inhibitor SLV338 in acute and chronic experimental renal damage. Clin Lab 2011; 57: 507-515.

49 Singh M, Mensah GA, Bakris G. Pathogenesis and clinical physiology of hypertension. Cardiol Clin 2010; 28: 545-559.

50 Feletou M, Verbeuren TJ, Vanhoutte PM. Endothelium-dependent contractions in SHR: a tale of prostanoid TP and IP receptors. Br J Pharmacol 2009; 156: 563-574.

51 Spijkers LJ, van den Akker RF, Janssen BJ, Debets JJ, De Mey JG, Stroes ES, van den Born BJ, Wijesinghe DS, Chalfant CE, MacAleese L, Eijkel GB, Heeren RM, Alewijnse AE, Peters SL. Hypertension is associated with marked alterations in sphingolipid biology: a potential role for ceramide. PLOS ONE 2011; 6: e21817.

$52 \mathrm{Wu}$ XC, Johns E, Michael J, Richards NT. Interdependence of contractile responses of rat small mesenteric arteries on nitric oxide and cyclo-oxygenase and lipoxygenase products of arachidonic acid. Br J Pharmacol 1994; 112: 360-368.

53 Battault S, Singh F, Gayrard S, Zoll J, Reboul C, Meyer G. Endothelial function does not improve with high-intensity continuous exercise training in SHR: implications of eNOS uncoupling. Hypertens Res 2016; 39: 70-78.

54 Parsons SJ, Hill A, Waldron GJ, Plane F, Garland CJ. The relative importance of nitric oxide and nitric oxide-independent mechanisms in acetylcholine-evoked dilatation of the rat mesenteric bed. Br J Pharmacol 1994; 113: 1275-1280.

55 Hilgers RH, Janssen GM, Fazzi GE, De Mey JG. Twenty-four-hour exposure to altered blood flow modifies endothelial $\mathrm{Ca} 2+$-activated $\mathrm{K}+$ channels in rat mesenteric arteries. J Pharmacol Exp Ther 2010; 333: 210-217.

56 Edwards G, Dora KA, Gardener MJ, Garland CJ, Weston AH. K+ is an endotheliumderived hyperpolarizing factor in rat arteries. Nature 1998; 396: 269-272.

57 Daull P, Jeng AY, Battistini B. Towards triple vasopeptidase inhibitors for the treatment of cardiovascular diseases. J Cardiovasc Pharmacol 2007; 50: 247-256. 